\title{
O suicídio amoroso: uma proposição metapsicológica
}

The amorous suicide: a metapsychological proposition

El suicidio amoroso: una proposición metapsicológica

\author{
Marcos Vinicius Brunhari* \\ Maria Livia Tourinho Moretto ${ }^{* *}$
}

\begin{abstract}
Resumo
A escuta de orientação psicanalítica àquele que relata uma tentativa de suicídio e a remete à ruptura de um relacionamento amoroso permite uma reflexão de cunho metapsicológico que sustente que a quebra do vínculo amoroso é recusada de tal forma que a precipitação suicida nisso se insira, a fim de manter algo que não pode ser perdido. Tomando a melancolia como paradigma para o suicídio, aponta-se uma recusa a partir da manutenção do amor. A assertiva freudiana de que o eu consente com a própria morte quando identificado ao objeto é passível de articulação com as proposiçōes de Lacan acerca de objeto de amor e o que transcende seus atributos. Acentuaremos como objeto a aquilo que está sob o invólucro amoroso e como este perfila, de forma fulgurante, na tentativa de suicídio.
\end{abstract}

Palavras-chave: Suicídio. Psicanálise. Amor. Melancolia.

\begin{abstract}
The psychoanalytical orientation listening to the one who reports a suicide attempt and refers it to a love relationship breaking up, allows a reflection of a metapsychological nature which supports that the rupture of a love bond is refused at such a level that the suicide precipitation has its inspirations in order to keep something that cannot be lost. Having melancholy as a paradigm to the suicide, it points to a refusal based on the maintenance of love. Freud's assertive that the ego consents with its own death when identified to the object is liable of articulation with Lacan's propositions about the object of love and to which transcends its own attributes. It will be stressed as object " $a$ " the one which is underneath the loving involucre and how it profiles in an effulgent way to the suicide attempt.
\end{abstract}

Keywords: Suicide. Psychoanalysis. Love. Melancholy.

\footnotetext{
Texto recebido em junho 2013 e aprovado para publicação em maio de 2014.

*Doutorando do Departamento de Psicologia Clínica do Instituto de Psicologia da USP (Bolsista CAPES). Endereço: Avenida Professor Mello Moraes, 1721, bloco F, sala 24 - Cidade Universitária, São Paulo-SP. CEP: 05508-030. E-mail: mvb_marcos@ yahoo.com.br.

"Docente do Departamento de Psicologia Clínica do Instituto de Psicologia da USP. Endereço: Avenida Professor Mello Moraes, 1721, bloco F, sala 24 - Cidade Universitária, São Paulo-SP. CEP: 05508-030.E-mail: liviamoretto@usp.br.
} 


\section{Resumen}

La escucha de orientación psicoanalítica a la persona que reporta un intento de suicidio y lo refiere a la ruptura de una relación amorosa permite una reflexión de carácter metapsicológico que defiende que la ruptura de un vínculo amoroso es rechazada de tal manera que la precipitación suicida aparece aquí para mantener algo que no puede ser perdido. Tomando la melancolía como paradigma para el suicidio, se señala un rechazo basado en el mantenimiento del amor. La asertiva de Freud, de que el "yo" consiente con su propia muerte cuando se identifica con el objeto, se hace susceptible de articulación con las proposiciones de Lacan sobre el objeto del amor y lo que trasciende sus atributos. Destacaremos como objeto aquello que está debajo del envolvimiento amoroso y cómo éste perfila de forma fulgurante en el intento de suicidio.

Palabras clave: Suicidio. Psicoanálisis. Amor. Melancolía.

A proposta deste artigo provém do trabalho clínico com pessoas que relatam tentativas de suicídio e remetem invariavelmente a causalidade de seus atos ao rompimento de uma relação amorosa. São homens e mulheres, de idades variadas, que trazem em seus discursos uma tentativa de suicídio bastante abrupta diante do término de um relacionamento amoroso marcado por uma intensidade comparável àquela que se expressa no ato.

Sustentamos a hipótese de que a quebra do vínculo amoroso como condição imposta pela pessoa amada é recusada de forma violenta, e a tentativa de suicídio nisso se insere, de modo a manter algo que não pode ser deixado. Para defender essa formulação, traremos uma reflexão metapsicológica que objetiva sistematizar aquilo que se observa desde a clínica, com premissas de Freud e de Lacan. Apontaremos, a seguir, que a recusa a perder algo pela via da manutenção do amor possa ser lida pelas coordenadas freudianas referentes à melancolia (Freud, 1996b). Partiremos da melancolia não como uma estrutura clínica ou como um estado marcado pelo humor desanimado, mas como um paradigma para que se compreenda o suicídio em Freud com base naquilo que Lacan (1962-1963/2005) anuncia como uma relação súbita com o objeto $a$. Será com o trabalho Luto e melancolia (Freud, 1917/1996) que articularemos aquilo a que chamamos de recusa a perder com o que Freud marca sobre na melancolia haver a manutenção do amor, por via identificatória, diante da perda do objeto. Munidos da assertiva freudiana segundo a qual o eu consente com a própria morte desde que esteja identificado a um objeto, avançaremos em nossa reflexão ao comentário de Lacan (1960-1961/2010) a respeito do amor enfatizando o 
objeto por trás dos atributos imaginários. Acentuaremos como objeto $a$ isso que está sob o invólucro amoroso e, com $O$ seminário, livro 10: a angústia (2005), como esse objeto é irredutível ao significante e como perfila, de forma fulgurante, na precipitação suicida.

Mas o queéisso a que chamamos de recusa a perder?É necessário que recorramos brevemente a alguns recortes de experiências clínicas que são ilustrativas dessa recusa, apenas para apontar nossa problemática de maneira mais clara. Por exemplo, na fala de um homem que, na época, contava com cerca de 30 anos, a namorada já vinha dando indícios do possível término do relacionamento e, após uma discussão referente ao extravio de um boleto bancário, ela disse que iria sair de casa e que o abandonaria. Na saída do portão, ele lhe disse; "Se você sair, você me perde". Bastou ela se dirigir ao portão que ele desferiu contra si próprio uma facada no abdômen. A faca já havia sido avistada no momento da discussão, pois afirma, muito emocionado, que pensou em matá-la. Contudo, após esfaquearse, a namorada retornou para auxiliá-lo e procurar socorro, visto que ele se esvaía em sangue, mas nos braços dela. Outro homem, com pouco mais de 40 anos, falou sobre uma situação muito similar, embora relatasse uma separação conjugal que havia acontecido há mais de três anos. Disse que vinha pensando em se matar ao longo do período em que vinha se sentindo triste e abandonado. Falou sobre esse sentimento de abandono como algo que permeasse sua vida nos demais âmbitos. Foi assim que, com a possibilidade de início de um novo relacionamento amoroso, viu-se em um estado de angústia extrema. Não sabia se tinha certeza sobre se deveria ir por esse caminho que se lhe mostrava e, nesse ponto, uma tentativa de suicídio aconteceu e impediu que esse relacionamento fosse adiante. Um tiro na barriga fez com que seus familiares o internassem em uma clínica psiquiátrica onde apenas recebe visitas destes.

O amor descrito nesses relacionamentos é, muitas vezes, comparado à intoxicação e à dependência química. A intensidade dessa relação não se inicia em qualquer contexto, acontece em momentos específicos da história dessas pessoas e se caracterizam por cenas de ciúmes e de servidão. Não avançaremos em detalhes referentes a esses casos e a outros, apenas nos ateremos ao que se mostra de tão radical na escuta a essas pessoas quando falam sobre a recusa a perder esse amor como substrato para a tentativa de suicídio. Nesse ponto, reconhecemos que a recusa se refere a algo que é da ordem do insuportável. Segundo Rabinovich (2002), "A perda do objeto de amor (ou a simples ameaça dessa perda) é insuportável para o sujeito, e onde o grau de dor e tristeza leva a limites do tolerável, o que conduz ao atentar contra sua vida" (p. 245). Portanto os desencadeamentos da perda do objeto de amor, nesses casos, são catastróficos e encontram no ato suicida uma desembocadura. 


\section{A recusa a partir do paradigma melancólico em Freud}

A recusa que é tão marcada na fala dessas pessoas e que é fenomenicamente observável na clínica é repleta de um sofrimento angustiante e de uma insuportabilidade levada às raias do extremo. A tentativa de suicídio que ocorre nesse contexto muitas vezes é alvo do mais completo desinteresse e de um julgamento que a relega ao lugar de algo que é apenas o de uma simulação, algo que não pode ser levado a sério. Não seguiremos por aí e, justamente por isso, reconhecemos que a recusa informada nesses relatos pertence a uma concatenação que envereda para a precipitação suicida. Nosso foco, neste artigo, está sobre a recusa a perder o amor e sua anterioridade à tentativa de suicídio. Assim, por um percurso que privilegia a metapsicologia freudiana, propomos articular isso a que nomeamos recusa com o que Freud traça acerca da melancolia. Tomaremos esta como um processo no qual, diante da perda do objeto, o amor por este sofre um desvio e retorna ao eu por identificação. Segundo Freud (1917/1996), "refugiando-se no ego, o amor escapa à extinção" (p. 262), e será dessa maneira que também o ódio passará a torturar o eu como se fosse o causador de toda a desgraça. Freud (1917/1996) vislumbrará nisso uma compreensão sobre o suicídio alicerçada na manutenção do amor. Para articular a recusa que aqui salientamos com essa manutenção do amor que Freud indica no processo melancólico, seguiremos por um trajeto que se inicia em um comentário do autor acerca do personagem Werther, de Goethe, até alcançar os pontos que competem à nossa proposta em "Luto e melancolia" (1917/1996).

Os trabalhos iniciais de Freud encontram, em suas cartas e manuscritos enviados a Fliess, os mais relevantes indicadores dos caminhos de organização e desenvolvimento da teoria psicanalítica. Nessas comunicações de Freud com seu interlocutor, estão presentes germes de conceitos fundamentais que virão a ser examinados posteriormente pelo autor. Destaquemos aqui, de acordo com nossos objetivos, o Rascunho $N$ (1897/1996), visto haver neste uma das primeiras referências do autor ao tema do suicídio. Dela poderemos extrair um fio condutor para nossas reflexões neste trabalho. Segundo Freud, no Rascunho $N(1897 / 1996)$ :

Para compor seu Werther, Goethe combinou algo que havia experimentado (seu amor por Lotte Kästner) e algo que tinha ouvido (o destino do jovem Jerusalém, que se suicidou). Provavelmente, Goethe estava brincando com a ideia de se matar; encontrou nisso um ponto de contato e identificou-se com Jerusalém, de quem tomou emprestado o motivo para sua própria história de amor. Por meio dessa fantasia, protegeu-se das consequências de sua experiência (p. 306). 
Este trecho do manuscrito aponta para a fantasia como uma proteção contra a tendência suicida emergente do fracasso amoroso. Como não ambicionamos aqui seguir por uma leitura biográfica de Goethe, propomos tomar esse trecho em um cunho metafórico desde o qual o jovem Werther representa a conjunção do suicídio de Jerusalém com o fracasso amoroso de Goethe, sendo o que protege seu criador da mesma experiência daquele. $\mathrm{O}$ impedimento não se estende ao personagem que é o porta-voz dos mais dilacerantes sofrimentos derivados de um amor impossível. Essa é uma das primeiras referências na obra de Freud sobre o suicídio, e consideramos relevante que ela seja feita exatamente em relação ao personagem de Goethe, Werther, e mais especificamente ao suicídio amoroso.

Inspirados por Freud, retomemos brevemente a obra Os sofrimentos do jovem Werther (Goethe, 2010) como um testemunho literário sobre nosso tema, com o objetivo de extrair um ponto que nos orientará em nossa discussão sobre a manutenção do amor ao objeto de acordo com Freud, em seu Luto e melancolia (1917/1996).

Essa obra é representante do romantismo literário iniciado ao término do século XVIII e marcante do século XIX. Traz em seu bojo o amor em sua forma mais idealizada. $\mathrm{O}$ amor versado pelo estilo romântico se caracteriza pela completude unificante entre os amantes, atravessada por uma nostalgia que torna o encontro entre as metades idealizado para um futuro e remetido a um passado. É desse modo que Werther conhece Charlotte, ou Lotte, e, de imediato, é advertido pelas amigas da moça de que esta já é comprometida com um típico burguês da época, Albert. Desde então, os primeiros encontros com Lotte serão repletos de inebriante paixão. Werther mal pode descrevê-la a seu amigo correspondente, Willerm, dada tamanha perfeição: "Não estou em condições de dizer-lhe como é perfeita, porque é perfeita: em resumo, cativou-me todo o ser" (p. 27). Será dessa forma abundante e idealizada que Lotte vai ser personificada ao longo da obra, até o fim trágico de Werther.

Werther relata, em cartas a Willerm, o mais arrebatador sentimento: "Sem ela, tudo significa nada" (p. 112). E a cada momento em que o encontro amoroso do personagem com sua amada se torna mais impossibilitado, seu sofrimento se intensifica. Seus planos de suicídio se tornam cada vez mais evidentes e, após um ato desesperado e violento em que Werther a beija, um tiro com uma das armas do marido de Lotte é a forma como o protagonista tira sua própria vida. O momento do beijo é descrito por Goethe (2010) da forma mais ilustradora possível do amor romântico: "O mundo já não existia para eles" (p. 149). Ou seja, a união amorosa é total a ponto de excluir o que resta dessa soma. Contudo, de forma interessante, é após esse momento de completa junção que Werther se mata: 
Tudo é transitório, mas nem mesmo a eternidade poderia apagar a chama viva que ontem colhi em seus lábios e agora ainda sinto em mim. Ela me ama! Estes braços a abraçaram, estes lábios tremeram sobre os seus, esta boca balbuciou colada à sua. Você é minha! Você é minha Lotte, para sempre! (Goethe, 2010, p. 152).

Tomemos essa frase como significativa para os nossos objetivos neste artigo. A transitoriedade, a impermanência, poderia apagar com o tempo este momento de extrema paixão entre Werther e Lotte. Esse momento disruptivo deixou marcas que o personagem se recusa a perder. Essas marcas certificam o amor correspondido e a posse da amada. Não prescindir da completude é o que o leva à morte, à eternização daquele momento abrupto e fugaz. Pode-se extrair dessa passagem literária algo que se apresenta na clínica: a recusa a perder algo revestido de valor ideal.

É a partir desse dado que trazemos aqui o artigo traduzido como Sobre a transitoriedade (1916/1996) em que Freud escreve sobre a impermanência e durabilidade das coisas. Não é insignificante dizer que este artigo é escrito a convite da Sociedade Goethe de Berlim e consta, em meio a outros de variados autores e artista da época, em um volume comemorativo do ano de 1916. Nele, o autor narra o diálogo em um passeio com um amigo e com um poeta. Nesse diálogo, Freud (1916/1996) opõe-se ao posicionamento do poeta que, na caminhada em um dia de verão, não extraia qualquer alegria da beleza que observava na natureza, pois, segundo defende, essa beleza tinha validade, estava fadada à destruição quando chegasse o inverno. Assim, concluía o poeta que toda a beleza estava destinada à impermanência e que tudo o que era amado e admirado perdia o valor na medida em que era finito. $O$ autor afirma não ter argumentado contra a impermanência do que é belo e amado, mas que isso não implica uma perda de seu valor, e sim o contrário. Uma maior valoração é dada àquilo que tem escassez no tempo, e esse ponto de vista leva Freud (1916/1996) a definir a posição do amigo e do poeta como "uma revolta em suas mentes contra o luto" (p. 318). Essa dificuldade em renunciar ao que se perde, coordenada pelo princípio de prazer, é componente do processo do luto e da melancolia. Assim, Freud (1916/1996) antecipa o que será publicado em seu Luto e melancolia (1917/1996) a respeito do luto e de sua consumação espontânea na proporção em que se renuncia ao que se perdeu. Veremos que, na melancolia, isso se torna um problema. 
A revolta que Freud (1916/1996) reconhece no comentário do poeta quanto à impermanência das coisas pode ser conjugada com o que se destaca do trecho da obra de Goethe (2010): que Werther anuncia sua autodestruição a partir do momento em que se recusa a perder o que obteve. Como característica do amor romântico, a inviabilidade de completude, de posse do objeto amado, é um direcionamento para a morte, para a destruiçáo. É assim que ele se mata em posse do amor do objeto e, assim, a morte é sinônimo da efetivação dessa conjunção. Não avançaremos sobre esses aspectos do estilo romântico, apenas acentuemos aqui a manutenção do amor do objeto no momento do ato suicida. ${ }^{1}$

Munidos dessa manutenção que a literatura nos permite observar, adentremos o artigo Luto e melancolia (1917/1996) com a finalidade de articular essa recusa a perder e a consequente manutenção do amor com as premissas freudianas sobre a melancolia.

Rapidamente, façamos uma breve menção aos primeiros escritos de Freud sobre o luto e a melancolia a fim de acrescentá-los à nossa discussão sobre o assunto. Nos primeiros escritos de Freud enviados a Fliess, luto e melancolia compõem pontos de interesse dignos de elaborações relevantes para nosso trabalho. Em um manuscrito inteiramente dedicado à melancolia, o Rascunho $G(1895 / 1996)$, Freud afirma ser o luto o afeto correspondente da melancolia, caracterizando-o como "o desejo de recuperar algo que foi perdido. Assim, na melancolia, deve tratar-se de uma perda - uma perda na vida pulsional” (p. 247). Estabelecido o binômio que perdurará ao longo de toda a psicanálise, o autor o conjuga em torno da perda e do desejo de recuperação. Ressaltamos que a melancolia tem um estatuto de perda que, ainda não totalmente diferenciado do luto, indica para um campo pulsional. Nesse período, Freud remete a perda melancólica ao representacional, à esfera psíquica. Segundo o autor, é um processo de profundo sofrimento metaforizado como uma "hemorragia interna" (p. 252), ou seja, as representações que compõem a esfera psíquica escoarão por uma ferida. Essa metáfora de Freud sintetiza o processo de miséria simbólica e o desarvoramento que se observam em quadros melancólicos.

Nesses primeiros escritos, verificamos que o binômio luto e melancolia já havia sido adotado por Freud (1895/1996), mas será apenas em 1915 que o autor estabeleceria um paralelo entre ambos os conceitos e encaminharia avanços metapsicológicos. Freud (1917/1996) os situa como reaçôes a uma perda, tendo a melancolia uma "disposição patológica" (p. 249) em sua base. Também

1 Nesse ponto de cruzamento entre a psicanálise e o estilo romântico, cabe uma breve ressalva a respeito da finitude e da morte. Segundo Loureiro (2002), embora se discuta o estatuto clássico ou romântico de Goethe, a concepção de morte arraigada em sua obra demonstra-se romântica conforme se fundamenta em uma ideia de "finitude transitória" (p. 331). A autora contrapõe, de forma brilhante, essa concepção que embasa a morte como um obstáculo superável àquela de Freud que é fundamentada em uma metapsicologia e caracterizada por um apontamento da completa negação da morte. 
reconhece que, em ambos, existe o desânimo penoso, o pesar, o desinteresse pelo mundo externo e a incapacidade de estabelecer vínculo amoroso. Contudo apenas a melancolia apresenta uma perturbação do sentimento de si. É possível afirmar que, mesmo que a melancolia também remeta à perda de um objeto amado, bem como o luto, nela existe uma "perda de natureza mais ideal" (p. 251).

A perda melancólica é descrita pelo autor como desconhecida e de ordem ideal. Uma noiva que é abandonada, é um exemplo utilizado por Freud, deixa claro quem foi perdido, mas, em se tratando da melancolia, não fica óbvio "o que perdeu nesse alguém” (Freud, 1917/1996, p. 251, grifo do autor). Essa menção de Freud é fundamental para o nosso trabalho, dela podemos vislumbrar que existe algo no cerne do objeto de amor e que isso toma proporçôes singulares na melancolia. É a partir dessa perda que o eu melancólico iniciará seu processo de autodegradação, jogando-se a si próprio na miséria e fomentando a supressão do apego à própria vida.

Freud marca o processo melancólico por sua característica "auto". O eu se autodegrada, atira-se na miséria e se julga vil por meio de um "agente crítico" (Freud, 1917/1996, p. 253) que toma parte do próprio eu como objeto de injuria e ódio. Esse agente futuramente será nomeado supereu, mas, já em 1915, propicia que se firme na melancolia uma perda que se desenrola no interior do próprio eu. Dessa maneira, as autoqueixas melancólicas apontam para "alguém que o paciente ama, amou ou deveria amar" (Freud, 1917/1996, p. 254), no entanto essas lamentações são deslocadas do objeto perdido para o eu melancólico pela via da identificação narcísica. Essa via identificatória é regida pela escolha narcísica, diferenciada por Freud (1914/1996) da escolha anaclítica ou de ligação, na qual o eu reconhece no objeto amoroso aspectos de si próprio. A destruição do laço com o objeto demonstra a base narcísica dessa escolha na proporção em que ocasiona uma regressão ao eu.

A destruição do vínculo com o objeto amoroso assinala que, na melancolia, uma fraca aderência a tal objeto ocasiona o retorno ao eu, sob a fórmula freudiana: "a sombra do objeto caiu sobre o ego" (p. 254). Doravante o eu é julgado como o objeto que partiu, visto trazer consigo essa perda que, em essência, edifica-se sobre a recusa a "renunciar à relação amorosa" (Freud, 1917/1996, p. 255). O amor não pode ser renunciado, mesmo que o objeto já tenha sido abandonado. E, junto com o amor antes voltado para o objeto, o autor salienta o concomitante retorno do ódio sobre o eu. O ódio se volta ao eu em forma de sadismo, e isso, mais adiante na obra de Freud, terá o supereu como representante do algoz que vocifera sobre o eu culpado. 
A autotortura do eu, baseada na não renúncia ao amor, é disposto por Freud como fundamental para a compreensão da tentativa de suicídio. Promulga-se, portanto, que o eu apenas poderá matar-se caso possa dirigir contra si próprio a hostilidade antes reservada ao objeto. Todavia, é necessário que se coloque em relevo, que a identificação com esse objeto é peculiar, pois é narcísica, e traz consigo não o objeto em forma maciça, mas sim uma sombra, que faz com que o eu se sobrepuje completamente à culpa, sem possibilidade de se defender. Esse objeto triunfa sobre o eu, esgotando-o e levando-o à própria morte.

O retorno do amor por via identificatória ao estado narcísico aponta o que Freud (1915/1996) reitera acerca da gênese narcísica do amor, em que a satisfação autoerótica da pulsão é o fundamento para os subsequentes processos de incorporação do objeto amado. Os entrelaçamentos entre amor e ódio estão sob a alcunha da ambivalência e antecipam os desenvolvimentos de Freud sobre a pulsão de vida e de morte. Circunscrevamos nosso escopo neste artigo ao que Freud (1917/1996) expõe em sua metapsicologia acerca da ruptura com o objeto amado e a não renúncia ao amor que se configura no quadro melancólico. É pela manutenção do amor, mesmo que o objeto não possa ser mantido, que a sombra cai sobre o eu, possibilitando que este passe a se autotorturar.

O império do objeto sobre o eu melancólico conduz Freud (1917/1996) a afirmar o seguinte: "Nas situações opostas, de paixão intensa e de suicídio, o ego é dominado pelo objeto, embora de maneiras totalmente diferentes" (p. 257). Segundo o autor, no suicídio, o eu é eclipsado pelo objeto; já na paixão intensa, figura o mais vigoroso investimento objetal. O investimento é tão impetuoso que uma pessoa apaixonada "parece desistir de sua própria personalidade em favor de uma catexia objetal" (Freud, 1914/1996, p. 83). O apaixonado representa o auge da libido objetal e a contrapartida do esvaziamento do eu.

O enaltecimento e idealização do objeto de amor constatado no apaixonamento intenso assemelham-se, nos termos freudianos, ao suicídio, conforme o objeto é triunfante sobre o eu miserável. Esse processo é claramente expresso em formato econômico, mas, em um nível tópico e dinâmico, é evidente a diferença. $\mathrm{Na}$ identificação sobre a qual se baseia a mortificação do eu, o objeto é abandonado em nome do amor que não pode ser renunciado; já na paixão, o que se instala é um estado de servidão em que o objeto é mantido e investido. Eis a oposição que Freud (1917/1996) mencionava entre paixão e suicídio. Embora haja essa oposição, podemos observar que não se distancia de um assemelhamento, já que o eu se torna um rebotalho em ambos os casos. Subjugado ao objeto que triunfa, o eu mantém-se amado, recusando-se a perder esse amor e castigando-se em nome dessa recusa. Assim, "na cegueira do amor, a falta de piedade é levada ao diapasão do crime" (Freud, 1921/1996, p. 123), no caso do suicídio, um crime 
contra si próprio que se caracteriza como passional por ter em seu fundamento a manutenção do amor por uma via sustentada pelo narcisismo.

Ao partirmos de Os sofrimentos do jovem Werther (Goethe, /2010) para indicar a recusa a perder o amor do objeto, fato que destacamos do relato de pessoas que referem tentativas de suicídio seguidas da ruptura de um relacionamento amoroso, defendemos que essa recusa poderia ser articulada à manutenção do amor diante da perda do objeto descrita por Freud (1917/1996) como parte do processo melancólico. Frisamos a base narcísica sobre a qual acontece esse processo em que a sombra do objeto irá se sobrepor ao eu. Freud reconhece nesse processo uma compreensão para o ato suicida, pois concomitantemente à manutenção do amor, haverá um retorno sobre o eu do sadismo antes dirigido ao objeto. Instalada a miséria do eu sob a rubrica de um objeto que triunfa, insistimos que é por uma sombra e não por um traço que esse objeto perpetra tais efeitos catastróficos. Assim, podemos compreender que, como no exemplo de Freud em que a noiva perde em seu noivo algo além deste, há, no objeto de amor, um cerne que, no processo melancólico, recai sobre o eu como uma sombra.

No próximo tópico deste artigo, seguiremos com a proposta de que há um cerne do objeto amoroso. Avançaremos, defendendo que, na tentativa de suicídio, de acordo com o paradigma melancólico, essa medula do objeto amoroso tem uma função particular. Recorreremos ao ensino de Lacan, em seu $O$ seminário, livro 8: a transferência (1960-1961/2010), para indicar isso que está dentro do invólucro do amor e, com O seminário, livro 10: a angústia (1962-1963/2005), especificaremos como objeto $a$ isso que é irredutível ao significante e que tem função privilegiada na tentativa de suicídio.

\section{As oscilações do amor e a queda do objeto $a$}

A manutenção do amor após a perda do objeto acontece pela via identificatória e permite observar que algo que transcende o objeto amoroso, de acordo com o modelo melancólico, posta-se sobre o eu, gerando efeitos catastróficos. Desde então, nos próximos parágrafos, avançaremos sobre os apontamentos de Lacan que nos permitirão melhor aprofundar nossas considerações sobre o suicídio amoroso.

De início, recuperemos alguns pontos de um período em que Lacan se debruça sobre a temática do amor. Em seu $O$ seminário, livro 8: a transferência (1960-1961/2010) apresenta uma leitura de O banquete (1972) de Platão com o objetivo de articular aquilo que se propóe acerca do amor com o que a psicanálise chama de transferência. Não acompanharemos aqui esse percurso do ensino de 
Lacan, apenas iremos nos ater aos comentários referentes ao amor e ao estatuto do objeto conforme esses dois temas se encadeiam em asserçôes pontuais do autor sobre o luto, a melancolia e o suicídio.

$\mathrm{Na}$ essência do que Lacan traz nesse período de seu ensino sobre o amor está a premissa de que "o amor é dar o que não se tem" (p. 49). Disso Lacan deriva duas funções, a do amante (érastès) e do amado (érôménos) localizando o primeiro como o sujeito do desejo e o segundo como o único a ter alguma coisa. Lacan questiona se aquilo que o amado possui é adequado ao que falta ao sujeito desejante, afirmando que o amor oferece condição propícia para se observar a inadequação do objeto ao desejo. A situação entre Sócrates e Alcibíades, retomada com base no texto platônico em referência, oportuniza a Lacan a observação sobre a inadequação e, no âmbito disso, o reconhecimento de que o objeto amoroso é o invólucro de outra coisa. Essa outra coisa tem valor precioso, é algo que está no interior, no cerne, e será nomeado por Lacan (2010) como "agalma" (p. 173), termo colhido no texto de Platão, da cena na qual se indaga Sócrates a fim de desmascará-lo e obter um sinal do desejo deste por Alcibíades.

Dois momentos de $O$ banquete (1972) são figurativos disso que Lacan destaca sobre a falta e o objeto. Um deles é o discurso de Aristófanes, o comediante, sobre os seres esféricos, derivados dos astros, que tinham três formas distintas: a feminina, a masculina e a andrógina. Eram robustos, formados por quatro pernas, quatro mãos, dois órgãos genitais e uma cabeça. Dada sua audácia e revolta, Zeus os separa em metades, com o intuito de enfraquecê-los. Doravante, essas metades têm as faces voltadas para sua cicatriz, o umbigo, para lembraremse do corte e se tornarem menos orgulhosas. Agora esses seres já não serão mais ensimesmados e limitados a si próprios. Eis a base para o amor ser compreendido como uma união das metades separadas. Segundo Platão (1972):

Por conseguinte, desde que a nossa natureza se multiplicou em duas, ansiava cada um por sua própria metade e a ela se unia, e envolvendo-se com as mãos e enlaçando-se um ao outro, no ardor de se confundirem, morriam de fome e de inércia em geral, por nada querer fazer longe do outro (p. 29).

Desde então, o amor é originado na procura de um pelo outro correspondente da antiga natureza, da completude. $\mathrm{O}$ encontro das duas partes impele à morte, por nostalgia da junção agora impossível, e é a representação do auge da ânsia amorosa que pende para a união total. 
O segundo momento que aqui recuperamos é o do discurso da sacerdotisa Diotima, trazido por Sócrates por afirmar dever a essa mulher aquilo que sabe sobre o amor. É assim que dá voz a essa personagem que chama a atenção para o fato de Eros não ser feio, embora não seja dotado de beleza. A sacerdotisa desenvolve, no diálogo com Sócrates, o mito do nascimento do amor, propondo este como gerado pela união da riqueza com a pobreza. Em ocasião do nascimento de Afrodite, Recurso, representante da riqueza e filho da Prudência, embriagase e adormece. A Pobreza, que mendigava as sobras à porta, deita-se ao lado de Recurso e concebe Eros. De sua progenitora, o amor herdará a miséria. Longe de ser belo, é também influenciado por seu pai, pois é audaz e desejante de sabedoria. Dessa maneira, vive entre a sabedoria e a tolice. Segundo Platão, "Não deseja portanto quem não imagina ser deficiente naquilo que não pensa the ser preciso" (1972, p. 41). De modo bastante ilustrativo, Lacan toma essa fórmula calcada na falta que a Pobreza tem a oferecer para o nascimento do amor. Essa característica será herdada por este.

O amor apenas pode ser articulado em torno da falta, pois o que deseja somente o tem por falta. É acerca tanto do mito dos seres esféricos quanto do discurso de Diotima que Lacan destaca a função metonímica do desejo e seu direcionamento a algo que estará sempre além de todos os objetos. É nesse ponto que insistimos aqui neste artigo, e será por meio da entrada de Alcibíades no cenário do banquete que Lacan localizará a topologia disso que está envolto pelo objeto amoroso, escamoteado. Segundo Lacan (1960-1961/2010), "Se esse objeto os apaixona é porque ali dentro, escondido nele, há o objeto do desejo, agalma” (p. 188). Essa afirmação insere toda a retomada das passagens de $O$ banquete (1972) alusivas à gênese e à natureza do amor por apresentarem o amor em sua circulação em torno de uma falta primordial. Esta tem função privilegiada na relação com o objeto.

Aquilo que circunda a falta do objeto, o invólucro amoroso, bordeja o que é o cerne, o ponto radical que coloca o sujeito em relação com o significante. O que destacamos com essa introdução do objeto envolto, de acordo com Lacan (19601961/2010) em sua retomada sobre o amor, é algo que escapa ao significante, que a ele não é reduzido. Falamos do objeto $a$. Nesse momento de seu ensino, esse objeto é concebido como objeto do desejo, é um objeto que aponta para a falta na base da constituição do sujeito. Segundo Rabinovich (2009), "O ponto de emergência do objeto próprio do amor se situa então precisamente ali onde o princípio do prazer interfere com seu para além, ali onde pode se constituir como um substituto possível do objeto perdido do desejo" (p. 33). O objeto de amor deriva de um para além do princípio do prazer como substituto do objeto do desejo, remetente da falta constitucional do sujeito. Seu invólucro imaginário, 
de substrato narcísico, como se observa desde Freud, encobre aquilo que escapa às raias do simbólico e do imaginário. Essa perspectiva permite compreender que o objeto sempre se encontra revestido de atributos narcísicos e que é continente de algo irredutível.

Lacan (1960-1961/2010), ao se referir à melancolia, afirma que, diferentemente do luto, em que os traços do objeto perdido são identificados um a um, na melancolia, a presença do objeto $a$ deslancha efeitos catastróficos. Os efeitos catastróficos da presença fulgurante do objeto $a$ na melancolia marcam o distanciamento daquilo que Freud chama de sentimento mais fundamental de apego à vida. No processo melancólico, transgride-se a imagem do eu em forma de um ataque a esta, com o objetivo de atingir algo que, como Freud (1917/1996) detectou, habita e perpassa o eu.

Como já acompanhamos, Freud (1917/1996) circunscreve o processo melancólico à relação com o objeto que triunfará sobre o eu miserável. A manifestação suicida acontece nesse meandro em que o ódio, antes voltado para o objeto, redireciona-se ao eu. Lacan (1960-1961/2010) inclui um novo elemento ao dizer sobre "um remorso de um certo tipo, desencadeado por um desenlace que é da ordem do suicídio do objeto" (p. 481). Lacan elege o remorso como um ponto de concorrência entre os termos do binômio luto e melancolia. O remorso é consequência do suicídio do objeto, ou seja, o objeto entrou no campo do desejo e de lá desapareceu, gerando culpabilização. Esse objeto ocupou um lugar sublime, de compatibilidade, e agora é despido revelando seu âmago e ratificando a falta mais fundamental.

Segundo Lacan (1960-1961/2010), "a mesma disposição se encontra por ocasião de determinada perda quando sobrevém durante esses longos amplexos entre sujeitos desejantes a que se chamam as oscilações do amor" (p. 481). A perda no plano da relação amorosa oferece ocasião para que se apresente o remorso que Lacan reconhece como ponto de concorrência entre luto e melancolia. Com essa citação, é possível transpor a disposição do remorso que envolve a perda melancólica para situaçôes de ruptura de um vínculo amoroso em que a recusa da perda do amor está estampada na fala daqueles que relatam uma tentativa de suicídio condicionada a tal rompimento.

O longo amplexo, como o mito platônico ilustra pela junção das partes separadas da antiga esfera e sua consequente morte pela nostalgia, é atravessado pela perda. Lacan fala em uma oscilação do amor. Nesse movimento, o amor deve ser resguardado e, com isso, o mais irredutível que o habita. Esse cerne, ao ser extraído, separado, pode gerar efeitos entre os quais localizamos a tentativa de suicídio. 
Propomos que, conforme o tal objeto amoroso entra no campo da partilha, daquilo que pode ser separado, a tentativa de suicídio pode surgir diante da angústia que emergirá dessa divisão. É em seu $O$ seminário, livro 10: a angústia (1962-1963/2005) que Lacan se ocupa de diferenciar dois tipos de objeto quanto a seu caráter de posse. O objeto que é partilhável pertence ao campo da troca, do roubo e da compra. É o objeto socializável, de aspecto imaginário, pois pode também pertencer ao outro semelhante. Diferentemente do objeto partilhável, existe a série de objetos não partilháveis, não especularizáveis e que são "anteriores à constituição do status do objeto comum, comunicável, socializado. Eis do que se trata no $a^{\prime \prime}$ (p. 103). Embora tenham a discrepância quanto ao caráter de posse, os objetos guardam um vínculo de causalidade, dada a anterioridade do objeto $a$ em relação aos partilháveis. A anterioridade do $a$ se expressa em uma operação que o dispõe como causa para o desejo, o qual se direciona aos objetos partilháveis. Exatamente nesse ponto, Lacan (1962-1963/2005) recorre às "perturbações da vida amorosa" (p. 105), delimitando que estas advêm a não ser do objeto $a$.

Por não ser especularizável, esse objeto escapa ao nível imaginário, materializando-se como uma borda a qual Lacan equivale a uma janela que marca o limite entre uma cena e o mundo. Sabemos que a janela é um limite muito comum em tentativas, e conclusões, de suicídio. Lacan não deixa de fazer menção a isso e o faz apropriando-se do verbo alemão, niederkommen, utilizado por Freud (1920/1996) quando este escreve sobre a tentativa de suicídio da Jovem Homossexual.

O verbo que tanto designa "dar à luz" quanto "vir abaixo" é utilizado por Freud (1920/1996) quando descreve a tentativa de suicídio da jovem que mantinha cortejamentos com uma dama de reputação questionável pela sociedade. Em dada ocasião, a jovem cruza com o pai em uma via pública, e ele a dirige um olhar fulminante que não prenuncia boa coisa. Ao tomar conhecimento da situação, a dama imediatamente encerra o que se dá entre as duas até então. Abruptamente, a jovem atira-se por um muro que desemboca em uma linha férrea subterrânea. Ela deixa-se cair da cena.

A queda da Jovem Homossexual é alvo de comentários de Freud (1920/1996), e o paradigma melancólico permeia a consideração de que o eu apenas pode atentar contra si no momento em que se identifica com um objeto. Assim, Freud (1920/1996, p. 174) menciona uma identificação da jovem com a mãe, que deveria ter morrido durante o nascimento do filho caçula. Repudiada pela dama e pelo olhar do pai, a jovem despenca. Segundo Lacan (1962-1963/2005), "O sujeito como que retorna à exclusão fundamental em que se sente” e, como um dejeto, um rebotalho, perfaz a primeira condição para a passagem ao ato: a 
identificação absoluta ao objeto $a$. O verbo niederkommen marca a saída de cena da jovem que cortejava a dama como se fosse um rapaz que se sobrepuja e pouco espera de sua amada idealizada.

Cabe observar que, nesse período de seu ensino, Lacan (1962-1963/2005) diferencia, de forma magistral, a passagem ao ato do acting out. A primeira se define pela identificação absoluta do sujeito ao objeto $a$, ao qual ele se reduz. Nesta, há uma saída da cena constituída pelo Outro e uma passagem para o mundo, onde o real se comprime; já o acting out opõe-se à passagem ao ato quando se constitui na conduta do sujeito como uma "mostração" (Lacan, 1962$1963 / 2005$, p.138) ao Outro. É uma entrada em cena na qual o que se mostra é a queda do objeto $a$.

Não pretendemos aqui situar as tentativas de suicídio às quais nos referimos sob a égide de uma forma ou outra. Consideramos que "todos esses fenômenos clínicos, que têm ar de uma disparidade completa, na verdade manifestam, fazem presente isso que escapa à cena" (Soler, 2012, p. 68). Assim, a distinção entre cena e mundo é o traço comum entre a passagem ao ato e o acting out e o que nos permite afirmar que a tentativa de suicídio seguida à ruptura amorosa privilegia a apresentação desse objeto dentro ou fora da cena.

Estabelecer a cena como do Outro é compreender que nela o sujeito se constitui, nela o sujeito é barrado pelo significante e disso resta o objeto que opera de forma unânime seja na passagem ao ato ou no acting out. Isso que escapa à cena, que Lacan (1962-1963/2005) relega ao mundo, caracteriza a aproximação ao real e é o eixo sobre o qual sustentamos o cerne do objeto amoroso. Esse cerne não pode entrar no campo da partilha e, diante da separação, leva em sua queda o sujeito atrelado.

\section{Considerações finais}

Desde a escuta clínica às pessoas que relatam tentativas de suicídio seguidas ao rompimento de uma relação amorosa, pôde-se asseverar a presença de uma recusa que perfila o discurso desses amantes e que é o esteio para a precipitação suicida. Essa recusa, evidenciada no somente depois da tentativa de suicídio, é índice de algo que deve ser mantido fora do campo da separação. Assim, por uma via metapsicológica, buscamos sustentar a hipótese de que algo não pode ser partilhado. Pelo paradigma melancólico, alcançamos a proposta de Freud (1917/1996) segundo a qual o eu apenas pode se matar conforme mata um objeto ao qual se identificou. A identificação apenas acontece quando, diante da perda do objeto, o amor é mantido pelo eu. Concomitantemente, o ódio, antes dirigido ao objeto, retorna sobre o eu e promove o processo de tortura que pode enveredar ao suicídio. 
O rompimento da relação com o objeto amoroso desencadeia um efeito catastrófico que guia a compreensão freudiana do suicídio. A recusa a perder, ao ser pensada com base no paradigma melancólico proposto por Freud em sua metapsicologia, situa algo que transcende o objeto e que habita seu cerne. Algo que não pode ser separado se configura nessa recusa explicitada pelos amantes abandonados. Desde Freud, pôde-se compreender que isso que é central no objeto amoroso é fulgurante na tentativa de suicídio em que a ruptura antecede a precipitação.

Não se permite a impermanência disso que está em jogo e que, nos termos freudianos, triunfa de maneira devastadora sobre o eu. Desse modo, articulamos esta proposta com o que Lacan (1960-1961/2010) afirma sobre o objeto agalma, algo que está no interior do objeto de amor. Ao conceber o amor disposto em torno da falta primordial, o objeto amoroso passa a ser um invólucro de algo precioso que escapa aos atributos simbólicos e imaginários. Assim, a presença do objeto a como cerne do objeto amoroso é referida por Lacan (1960-1961/2010) em relação à melancolia e à perda no plano da relação amorosa. Em ambas as situações, o objeto ocupou posição privilegiada e dali desapareceu, causando remorso.

A perda no plano da relação amorosa revela o âmago do objeto. Enquanto o objeto $a$ entra no campo da partilha é que efeitos se manifestam. Reconhecemos a tentativa de suicídio como um fenômeno clínico que se apresenta em relação a esse objeto. Assim, acompanhamos Lacan (1962-1963/2005) assinalar a anterioridade do objeto $a$ em relação aos demais que pertencem ao campo dos objetos partilháveis. A ausência de especularização desse objeto leva Lacan a referi-lo como uma borda, um limite entre a cena e o mundo. Diferenciando a cena como constituída pelo Outro, em que o sujeito é historicizado, e o mundo no qual se comprime o real, Lacan inscreve o objeto $a$ no campo daquilo que escapa à cena.

A tentativa de suicídio pode ser compreendida como representante de um momento ímpar, em que o objeto $a$ triunfa sobre a cena constituída pelo Outro. Assim, a recusa a perder algo aponta para o objeto a que ocupa o cerne do invólucro amoroso e que não pode ser submetido à partilha, e o suicídio amoroso é uma situação bastante privilegiada para se indicar a relação do sujeito com o $a$ no momento da precipitação suicida. 


\section{Referências}

Freud, S. (1996). A psicogênese de um caso de homossexualismo numa mulher (J. Salomão, Trad.). In S. Freud, Edição standard brasileira das obras psicológicas completas de Sigmund Freud (Vol. 18, pp. 153-183). Rio de Janeiro: Imago. (Trabalho original publicado em 1920)

Freud, S. (1996). Luto e melancolia (J. Salomão, Trad.). In S. Freud, Edição standard brasileira das obras psicológicas completas de Sigmund Freud (Vol. 14, pp. 243-279). Rio de Janeiro: Imago. (Trabalho original publicado em 1917)

Freud, S. (1996). Os instintos e suas vicissitudes (J. Salomão, Trad.). In S. Freud, Edição standard brasileira das obras psicológicas completas de Sigmund Freud (Vol. 14, pp. 115-144). Rio de Janeiro: Imago. (Trabalho original publicado em 1915)

Freud, S. (1996). Psicologia de grupo e a análise do ego (J. Salomão, Trad.). In S. Freud, Edição standard brasileira das obras psicológicas completas de Sigmund Freud (Vol. 18, pp. 77-154). Rio de Janeiro: Imago. (Trabalho original publicado em 1921)

Freud, S. (1996). Rascunho G: melancolia (J. Salomão, Trad.). In S. Freud, Edição standard brasileira das obras psicológicas completas de Sigmund Freud (Vol. 1, pp. 246-253). Rio de Janeiro: Imago. (Trabalho original publicado em 1895)

Freud, S. (1996). Rascunho N: notas III (J. Salomão, Trad.). In S. Freud, Edição standard brasileira das obras psicológicas completas de Sigmund Freud (Vol.1, pp. 304-307). Rio de Janeiro: Imago. (Trabalho original publicado em 1897)

Freud, S. (1996). Sobre a transitoriedade (J. Salomão, Trad.). In S. Freud, Edição standard brasileira das obras psicológicas completas de Sigmund Freud (Vol. 14, pp. 313-319). Rio de Janeiro: Imago. (Trabalho original publicado em 1916)

Freud, S. (1996). Sobre o narcisismo: uma introdução (J. Salomão, Trad.). In S. Freud, Edição standard brasileira das obras psicológicas completas de Sigmund Freud (Vol. 14, pp. 75-113). Rio de Janeiro: Imago. (Trabalho original publicado em 1914)

Goethe, J. W. (2010). Os sofrimentos do jovem Werther. São Paulo: Abril. (Trabalho original publicado em 1774) 
Lacan, J. (2010). O seminário, livro 8: a transferência. Rio de Janeiro: Jorge Zahar. (Trabalho original publicado em 1960-1961)

Lacan, J. (2005). O seminário, livro 10: a angústia. Rio de Janeiro: Jorge Zahar. (Trabalho original publicado em 1962-1963)

Loureiro, I. (2002). O carvalho e o pinheiro: Freud e o estilo romântico. São Paulo: Escuta.

Platão. (1972). O banquete. In Platão, Diálogos. (pp. 8-59). São Paulo: Abril Cultural. (Coleção Os Pensadores)

Rabinovich, D. S. (2009). O conceito de objeto na teoria psicanalitica. Rio de Janeiro: Companhia de Freud.

Rabinovich, D. S. (2002). Du suicide amoureux. In G. Morel, Clinique du suicide (pp. 245-250). Ramonville Saint-Agne: Érès.

Soler, C. (2012). Seminário de leitura de texto ano 2006-2007: Seminário A anguistia, de Jacques Lacan. São Paulo: Escuta. 